Original Article

doi:10.29052/IJEHSR.v6.i1.2018.08-15

\title{
Hepatic Steatosis: Can herbs cure this?
}

\section{Rabia Rehan ${ }^{1}$, Khalida Perveen ${ }^{1}$, Fauzia Imtiaz ${ }^{2}$ \& Sahar Mubeen ${ }^{1}$}

1. Department of Anatomy, Dow International Medical College,

Dow University of Health Sciences

2. Department of Biochemistry, Dow International Medical College,

Dow University of Health Sciences

Corresponding Author Email: f.imtiaz@duhs.edu.pk

Received 7/2/2018; Accepted 16/3/2018; Published: 31/03/2018

\section{Abstract}

Background: Accumulation of fat in the liver is known as liver steatosis which occurs as a result of obesity. Ginsenoside is glycosylated saponins easily found in Asia, Egypt and China. The aim of this study is to determine the role ginseng in treating fatty changes of liver measured by weight, size, and enzymes.

Methodology: It was an experimental study on animals. Ginseng root extract was prepared under expert supervision. Fifty male rats were divided into five groups each has to contain ten animals. Group 1 on balanced diet (control), Group 2 on high fat diet (HFD) obese control, Group 3 on HFD + Ginsenoside (100mg/kg body weight), Group 4 on HFD + Ginsenoside (200mg/kg body weight) and Group 5 on HFD + Ginsenoside $(400 \mathrm{mg} / \mathrm{kg}$ body weight). Animals were weighted at commencement then weekly and finally before sacrifice. Animals were sacrificed under chloroform anesthesia, the liver was isolated and removed. Liver weight and size were measured. Blood was collected through cardiac puncture and sent to DDRRL for LFT.

Results: By giving HFD, increase in liver weight, as well as the liver size and liver enzymes, was observed. Ginsenoside when given to HFD induced liver steatosis leads to decrease in liver weight, liver size, and liver enzymes. It had a prompt effect on reducing body weight as well as liver weight by reducing fat contents of the body.

Conclusion: The study provides evidence that Ginsenoside has hepatoprotective effects by reducing the weight, size, and enzymes of the liver.

\section{Keywords}

Hepatosis, Ginseng, Liver function test, Ginsenoside

\section{Introduction}

In this era due to a sedentary lifestyle and food patterns, there is a remarkable increase in weight which leads to metabolic syndromes like diabetes mellitus, hypertension, hyperlipidemia, obesity and coronary artery diseases by altering body metabolism ${ }^{1}$. A high-fat diet has a positive correlation with weight gain and fatty liver changes $^{2}$. The liver is the main organ of metabolism including both catabolism and anabolism. Human and rats both belong to a mammalian group and the microscopic structure and functions are similar so for study purpose rat liver is selected. The functional unit of the liver is named Lobule; Classical Lobule, Portal Lobule, and Acinus. Liver cells or
Hepatocytes are arranged radially from central vein forming two cell thicken hepatic plates. Sinusoids are blood-filled spaces between hepatic plates. Blood comes from intestine resides in sinusoids, hepatocytes take nutrients from that blood and make ATP (Adenosine triphosphate) through metabolism. ATP also known as energy coins uses in performing functions of the body. For an active and healthy body, liver should function perfectly. Hepatocytes have a capability to store fats and glucose (Glycogen). But more deposition of fats inside the cell effect on its functions. Liver function is impaired due to the accumulation of fats in hepatic cells, observed by liver function tests (LFT) ${ }^{3}$. The weight and size of the liver are increased after taking 
fatty meals for a long time. Fatty liver can occur by alcoholism which is very common in alcohol addicts, can also be produced by drugs and carbon tetrachloride poisoning ${ }^{4}$. The liver is the grey area to be focused here which needs attention as liver patients feel lethargy, fatigue, anorexia, nausea and have weight loss symptoms but clinician reach to diagnosis at advanced stage ${ }^{5}$. If liver disease identified in early fatty changes it is easy to reverse as compared to its cascade of reactions like inflammation (Hepatitis) and fibrosis (Cirrhosis) that leads to liver failure and cancers ${ }^{6}$.

To treat the root causes of non-alcoholic fatty liver disease (NAFLD) by means of any herb which has minimal or no side effects. Ginseng is, a herb used for treating fatty liver by decreasing sugar levels and fats by activating adenosine monophosphate kinase (AMPK) signaling pathways, which in turn decreases gluconeogenesis resulting in decreased glucose production by the liver, can be used for treating obesity as well as fatty liver (hepatic steatosis) ${ }^{7}$. AMPK downregulating the genes responsible for encoding enzymes required in gluconeogenic pathways.

The study was designed to see the effect of ginseng extract used to get rid of obesity and nonalcoholic fatty liver disease, preventing disease and reducing economical health burden. There are many drugs which reduce fat content by decreasing absorption from villi $^{8}$, decreasing appetite by hypothalamus ${ }^{9}$ and altering stomach capacity and satiety values ${ }^{10}$. The main purpose to choose ginseng is its mechanism of action which targets on a genetic level to increase glucose uptake by muscles ${ }^{11}$. It acts on the liver to decrease fatty acid uptake and oxidation, decreasing synthesis of cholesterol, triglyceride, fatty acids and glucose $\mathrm{e}^{12}$.

The present study was based on the hypothesis that administration of ginseng root extract reduced the fatty changes of liver measured by liver weight, size and LFT (SGPT, SGOT, and ALPO4).

\section{Methodology}

This is an experimental study in which rats were used as animal models. This study was conducted at Institute of basic medical sciences (IBMS), Dow University of health sciences (DUHS) with the collaboration of animal house and assistance of Dow diagnostic Research and reference laboratory (DDRRL). The permission was taken by an ethical committee of DUHS that is by an institutional review board (IRB).

The sample size was calculated by open epi calculator, as 30, it was found 6 animals per group. For reducing chances of error 10 animals per group was taken. There were 50 albino rats divided into 5 groups. Ginseng is glycosylated saponins, easily found in Asia, China and Egypt. In humans, ginseng root extract can be taken orally ${ }^{13}$. Ginseng root extract was prepared by soaking grinded ginseng root in ethanol and evaporating by rotatory evaporator with a vacuum pump in IBBPS (Institute of biological biochemical and pharmaceuticals sciences).

Group 1 was taken as a control, with normal balanced diet. Group 2 was on a fat diet (High-fat diet containing $32.4 \%$ calories from animal fat, while normal balanced diet contains $11 \%$ calories from fat). Group 3 was on ginseng treatment taking high-fat diet plus ginseng in a dose of $100 \mathrm{mg} / \mathrm{kg}$ body weight. Group 4 was taken HFD plus ginseng in the dose of $200 \mathrm{mg} / \mathrm{kg}$ body weight. Group 5 was taken HFD plus ginseng in the dose of $400 \mathrm{mg} / \mathrm{kg}$ body weight. Only male rats were taken just to avoid mating and reproductive cycle variation as seen in females.

High-fat diet was prepared in the animal house of Dow University under expert guidance by mixing of beef tallow with butter, cheese, methionine and normal diet (containing Carbohydrates, Proteins, and fats $)^{1}$.

Animals were purchased from the Animal house, caged separately according to groups, weight at the time of commencement then weekly and finally 
before sacrifice. Group 1 was provided normal balanced diet while group 2, 3, 4 and 5 was on a High fat diet (HFD). After 6 weeks group, 1 and 2 were sacrificed under anesthesia, blood was collected by cardiac puncture and collected in LFT tubes for lab test sent to DDRRL (Dow diagnostic research and reference laboratory). Group 3, 4 and 5 were treated with ginseng root extract orally once daily for further 6 weeks 100, 200 and $400 \mathrm{mg} / \mathrm{kg}$ body weight respectively. After 12 weeks group 3, 4 and 5 were sacrificed, blood was collected for LFT. Data were obtained for all 5 groups about, liver weight, size, and enzymes (SGPT, SGOT and Alk PO4). The data were analyzed using SPSS version 21. To evaluate the significance between groups one-way analysis of variance (ANOVA) was applied. $\mathrm{P}$ value $<0.05$ was considered significant with $95 \%$ confidence interval. Post hoc Dunnett ttest was applied after significant p-value to compare different groups with control.

\section{Results}

The current study based on obesity developed by high-fat diet in albino rats then treated with ginseng root extract to reverse the gained weight of liver, its size, and enzymes. The comparison was done among different groups in the experiment and they were labeled as I and $\mathrm{J}$ in the tables.

Table 1: Comparison of mean liver weight in different groups.

\begin{tabular}{lcccccc}
\hline Rats & N & Mean & $\begin{array}{c}\text { Standard } \\
\text { Deviation }\end{array}$ & $\begin{array}{c}\text { Standard } \\
\text { Error }\end{array}$ & \multicolumn{2}{c}{ 95\% Confidence Interval for Mean } \\
\cline { 6 - 7 } & & & Lower Bound & Upper Bound \\
\hline Group 1 & 10 & 4.7700 & 1.27980 & .40471 & 3.8545 & 5.6855 \\
\hline Group 2 & 10 & 9.3060 & 1.95810 & .61920 & 7.9053 & 10.7067 \\
\hline Group 3 & 10 & 7.2100 & 2.10631 & .66607 & 5.7032 & 8.7168 \\
\hline Group 4 & 10 & 7.6800 & 1.48009 & .46805 & 6.6212 & 8.7388 \\
\hline Group 5 & 10 & 5.3900 & 1.55310 & .49113 & 4.2790 & 6.5010 \\
\hline
\end{tabular}

Animals were purchased from DUHS Animal house. The liver was weighted just after dissection. The mean liver weight was observed with standard deviation (S.D) and range. Significant P-Value $=0.00$ was obtained by ANOVA (one-way analysis of variance) as shown in table 2. Post hoc Dunnett t-test was applied to compare the mean liver weight of groups with control. There is a highly significant increase in liver weight of group 2 (on a high fat diet) as compared to group 1 (on a standard diet). The decrease in liver weight observed in group 3,4 and 5 depending on ginseng root extract dosage.

\section{Table 2: Post Hoc Multiple Comparisons Dunnett t-Test of Liver Weight}

\begin{tabular}{|c|c|c|c|c|c|c|}
\hline \multirow[t]{2}{*}{ (I) Group } & \multirow[t]{2}{*}{ (J) Group } & \multirow{2}{*}{$\begin{array}{c}\text { Mean } \\
\text { Difference } \\
\text { (I-J) }\end{array}$} & \multirow{2}{*}{$\begin{array}{l}\text { Standard } \\
\text { Error }\end{array}$} & \multirow[t]{2}{*}{ P-value } & \multicolumn{2}{|c|}{ 95\% Confidence Interval for Mean } \\
\hline & & & & & Lower Bound & Upper Bound \\
\hline Group 2 & Group 1 & $4.53600 *$ & .76188 & .000 & 2.6075 & 6.4645 \\
\hline Group 3 & Group 1 & $2.44000 *$ & .76188 & .009 & .5115 & 4.3685 \\
\hline Group 4 & Group 1 & $2.91000 *$ & .76188 & .002 & .9815 & 4.8385 \\
\hline Group 5 & Group 1 & .62000 & .76188 & .832 & -1.3085 & 2.5485 \\
\hline Group 3 & Group 2 & $-2.09600 *$ & .80229 & .035 & -4.0633 & -.1287 \\
\hline Group 4 & Group 2 & -1.62600 & .80229 & .124 & -3.5933 & .3413 \\
\hline Group 5 & Group 2 & $-3.91600 *$ & .80229 & .000 & -5.8833 & -1.9487 \\
\hline
\end{tabular}


Liver size is also altered by taking high-fat diet, the drastic increase is observed while by taking ginsenoside remarkable decrease in size is observed. Liver of all groups was measured just after dissection. The mean liver size (length $\times$ breath $\times$ height) with standard deviation (S.D) and range as shown in table 3 Significant P-Value $=0.000$ was obtained by ANOVA (one-way analysis of variance).

Table 3: Mean Size of the liver of rats in different groups

\begin{tabular}{ccccccc}
\hline Rats & n & Mean & $\begin{array}{c}\text { Standard } \\
\text { Deviation }\end{array}$ & $\begin{array}{c}\text { Standard } \\
\text { Error }\end{array}$ & \multicolumn{2}{c}{$\begin{array}{c}\text { 95\% Confidence Interval for Mean } \\
\text { Lower Bound }\end{array}$} \\
\hline Group 1 & 10 & 19.2800 & 4.81844 & 1.52372 & 15.8331 & Upper Bound \\
\hline Group 2 & 10 & 51.5500 & 19.79401 & 6.25942 & 37.3902 & 65.7098 \\
\hline Group 3 & 10 & 35.4450 & 15.29260 & 4.83594 & 24.5053 & 46.3847 \\
\hline Group 4 & 10 & 26.2800 & 8.78266 & 2.77732 & 19.9973 & 32.5627 \\
\hline Group 5 & 10 & 16.7950 & 4.57544 & 1.44688 & 13.5219 & 20.0681 \\
\hline
\end{tabular}

$*^{n}$ is the number of animals in each group.

Post hoc Dunnett t-test was applied to compare mean liver size between groups, there were significant changes between group 1 and 2, 2 and 3,2 and 4 and 2and 5 as mentioned in table 4. Hence this table demonstrates the significant increase in liver size by taking fatty meal and liver size reduced significantly by taking ginseng root extract. Liver functioning is investigated through liver markers SGPT, SGOT, and ALPO4.

Table 4: Post Hoc Multiple Comparisons Dunnett t-Test of Size of liver

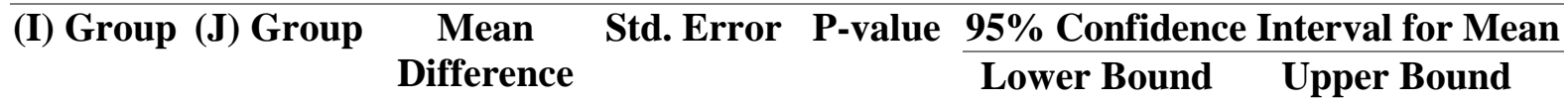

\begin{tabular}{lcccccc}
\multicolumn{7}{c}{$(\mathbf{I}-\mathbf{J})$} \\
\hline Group 2 & Group 1 & $32.27000 *$ & 5.46609 & .000 & 18.4337 & 46.1063 \\
\hline Group 3 & Group 1 & $16.16500 *$ & 5.46609 & .017 & 2.3287 & 30.0013 \\
\hline Group 4 & Group 1 & 7.00000 & 5.46609 & .518 & -6.8363 & 20.8363 \\
\hline Group 5 & Group 1 & -2.48500 & 5.46609 & .974 & -16.3213 & 11.3513 \\
\hline Group 3 & Group 2 & $-16.10500 *$ & 6.01555 & .030 & -30.8560 & -1.3540 \\
\hline Group 4 & Group 2 & $-25.27000 *$ & 6.01555 & .000 & -40.0210 & -10.5190 \\
\hline Group 5 & Group 2 & $-34.75500^{*}$ & 6.01555 & .000 & -49.5060 & -20.0040 \\
\hline
\end{tabular}

\section{Graph 1: Mean SGPT in different groups}

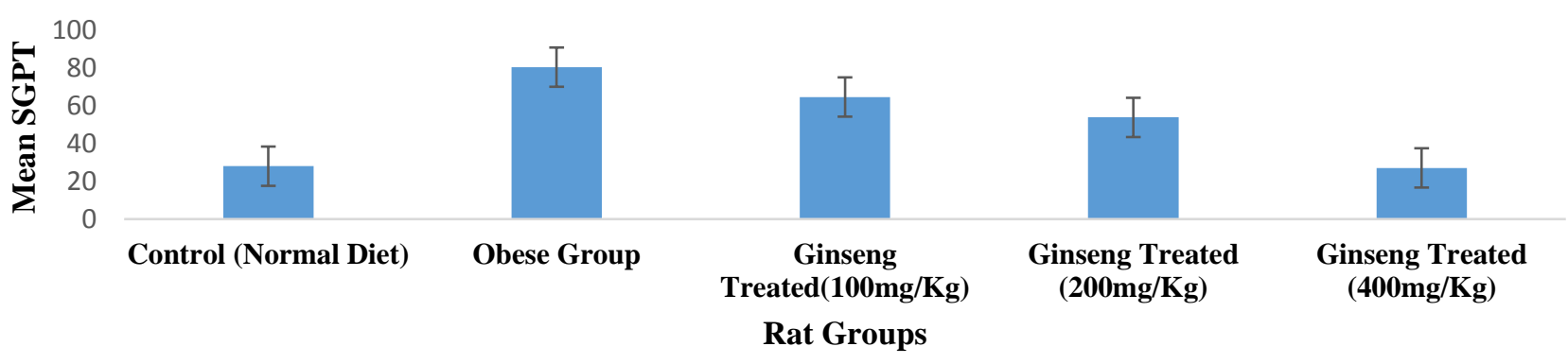


SGPT/ALT is the liver marker denoting the liver functions and its elevated levels evidence its damage. The mean SGPT (ALT) of all groups was obtained by liver function test as depicted in graph 1.

SGOT is another liver marker demonstrating the liver condition. The mean SGOT (AST) of different groups is mentioned in table 5. Significant P-Value $=0.00$ was obtained by ANOVA (one-way analysis of variance).

Table 5: Mean SGOT (AST) Of Different Groups

\begin{tabular}{lcccccc}
\hline Rats & n & Mean & $\begin{array}{c}\text { Standard } \\
\text { Deviation }\end{array}$ & $\begin{array}{c}\text { Standard } \\
\text { Error }\end{array}$ & \multicolumn{2}{c}{ 95\% Confidence Interval for Mean } \\
\cline { 6 - 7 } & & & Lower Bound & Upper Bound \\
\hline Group 1 & 10 & 121.9000 & 33.82783 & 10.69730 & 97.7010 & 146.0990 \\
\hline Group 2 & 10 & 175.0000 & 13.88044 & 4.38938 & 165.0705 & 184.9295 \\
\hline Group 3 & 10 & 142.3000 & 13.71982 & 4.33859 & 132.4854 & 152.1146 \\
\hline Group 4 & 10 & 130.1000 & 8.96227 & 2.83412 & 123.6888 & 136.5112 \\
\hline Group 5 & 10 & 117.2000 & 24.88552 & 7.86949 & 99.3980 & 135.0020 \\
\hline
\end{tabular}

\section{Graph 2: Mean SGOT of different groups}

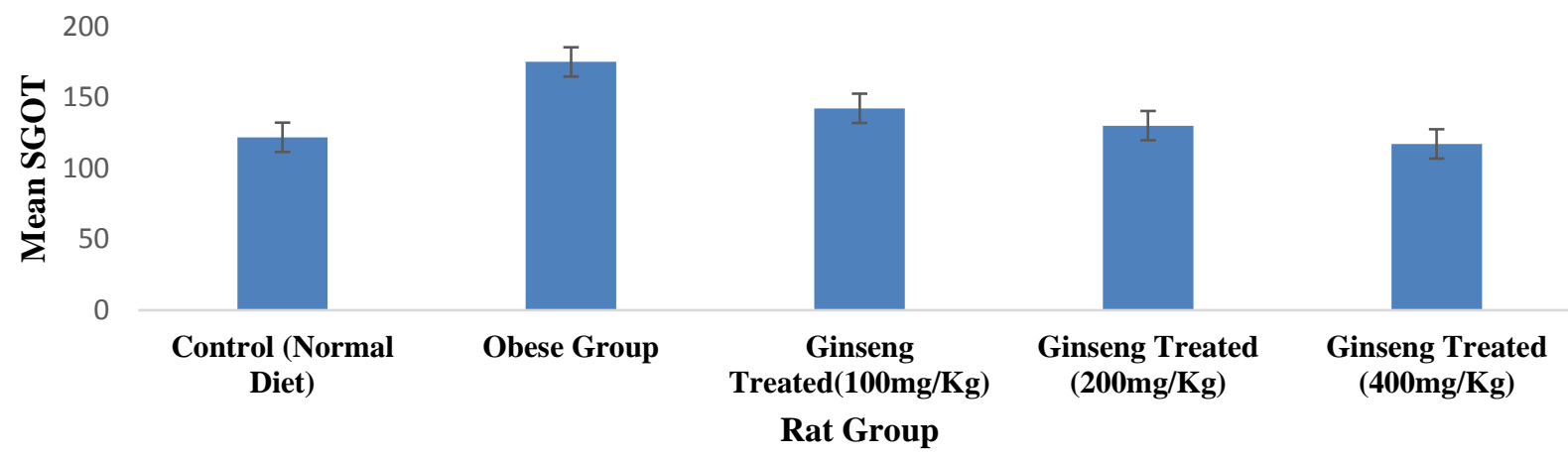

Post hoc Dunnett t-test was applied to compare mean between groups, there were significant changes between group 1 and 2, 2 and 3,2 and 4 and 2and 5 as shown in graph 2 It was noticed that there was increased in SGOT in Obese group due to fatty diet which in turn decreased by taking ginseng root extract gradually in dose-dependent manner.

The mean alkaline phosphatase (ALP) of different groups shows in table 6. Significant P-Value $=0.00$ was obtained by ANOVA (one-way analysis of variance). Post hoc Dunnett t-test was applied to compare mean between groups, there were significant changes between group 1 and 2,2 and 3, 2 and 4 and 2 and 5.

Table 6: Mean of ALP of rats in different groups.

\begin{tabular}{lcccccc}
\hline Rats & n & Mean & $\begin{array}{c}\text { Standard } \\
\text { Deviation }\end{array}$ & $\begin{array}{c}\text { Standard } \\
\text { Error }\end{array}$ & \multicolumn{2}{c}{ 95\% Confidence Interval for Mean } \\
\cline { 6 - 7 } & & & Lower Bound & Upper Bound \\
\hline Group 1 & 10 & 70.0000 & 14.97405 & 4.73521 & 59.2882 & 80.7118 \\
\hline Group 2 & 10 & 257.9000 & 157.27291 & 49.73406 & 145.3937 & 370.4063 \\
\hline
\end{tabular}




\begin{tabular}{lcccccc}
\hline Group 3 & 10 & 127.0000 & 91.97584 & 29.08532 & 61.2044 & 192.7956 \\
\hline Group 4 & 10 & 111.4000 & 71.38503 & 22.57393 & 60.3342 & 162.4658 \\
\hline Group 5 & 10 & 50.4000 & 14.07283 & 4.45022 & 40.3329 & 60.4671
\end{tabular}

$\mathrm{n}^{*}$ is number of animals in each group

It is evidenced that there was increased in ALP in the Obese group due to a fatty diet which in turn decreased by taking ginseng root extract gradually in dose-dependent manner(graph 3).

\section{Graph 3: Mean ALP of different groups}

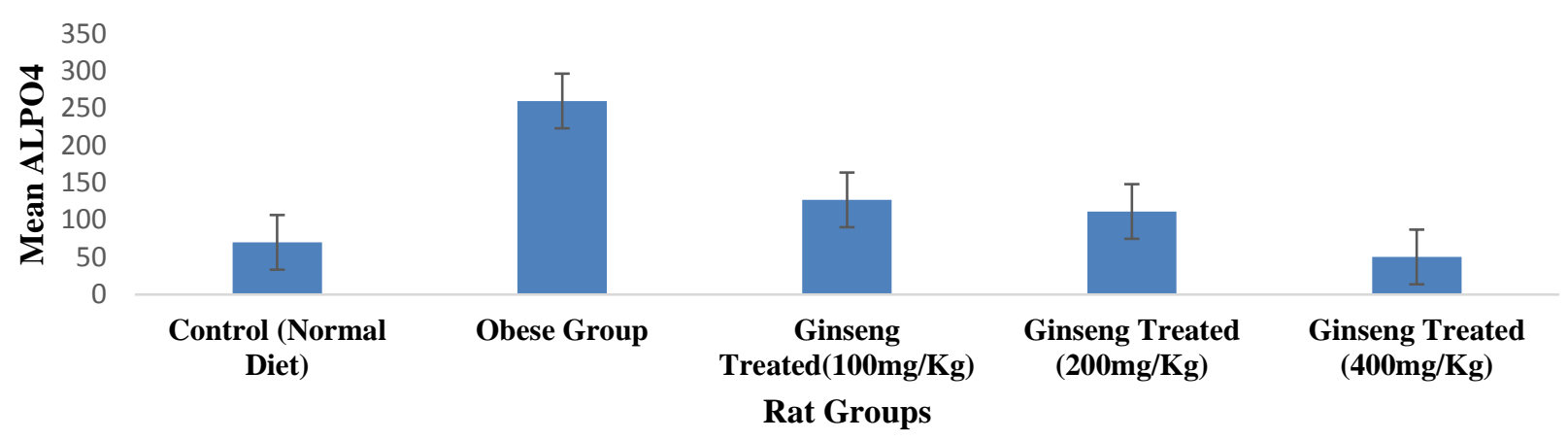

\section{Discussion}

Fatty liver was produced by dietary fats as it is concerned a common cause of NAFLD in our community. One out of three individual has NAFLD in western countries ${ }^{14}$. This study is focused on the effects of a fatty meal on liver morphology as well as its biomarkers. It also provides the solution of nonalcoholic fatty liver disease by means of an herb ginseng, which is easily available in Asia, Africa, and Egypt. It is evidenced by many researchers that its root extract is more potent ${ }^{15}$.

Rats were used as an animal model as its anatomy has a much resemblance with human anatomy ${ }^{16}$.A similar study was done in Korea in 2015, the only difference, they use black Korean ginseng instead of red Korean ginseng they also obtained the same finding ${ }^{17}$. The same species were also used by many workers and they suggested red ginseng may have the potential to ameliorate alcoholic fatty liver by suppressing inappropriate lysis of adipose tissue and preventing unnecessary de novo lipogenesis in the liver, which is mediated by AMPK signaling pathways ${ }^{18}$.
The present study makes a contribution in the field of liver damage by a fatty diet, not focused on NAFLD as a side effect of alcohol, drugs like carbon tetrachloride (CCL4) and high carbohydrate diet used by other researchers ${ }^{4}$. Ginseng extract had an anti- fibrosis effect via the regulation of the TGF$\beta 1 /$ Smad signaling pathway in the CCl4- induced liver fibrosis model. The major target was the inhibition of the expression of TGF- $\beta 1$, Smad2, and $\operatorname{Smad} 33^{19}$.

Different part of the world conducted the similar studies and proposed that KRG and its primary ginsenosides appear to have a range of beneficial effects in the context of CLD, a condition that encompasses NAFLD, alcoholic liver disease, chronic viral hepatitis, and $\mathrm{HCC}^{20}$. A research was conducted in South Korea, suggested that ginseng has unique beneficial effects on glucose metabolism and also in controlling the body weight in an obese animal model with insulin resistance it could be done by changing the expression of genes involved in glucose and fatty acid metabolism ${ }^{11}$. KRG may also show its effectiveness in reducing the proinflammatory cytokine and fatigue in obese patients 
with NAFLD, in addition to improvements in levels of adiponectin ${ }^{21}$.

This experiment showed that fatty diet injured the liver tissues resulting in increased level of enzymes which was treated by ginseng root extract administration. Ginseng has no side effects on human as proved by many researchers. The antiobesity, antidiabetic, hepatoprotective, antihyperlipidemic and antioxidant activities were also observed when red ginseng extract given to obese diabetic rats ${ }^{22}$.

\section{Conclusion}

The high-fat diet is a major source of obesity leading to its effect on various body organs. The liver was focused as it is a metabolic factory, leading to metabolic disorders. Ginseng provides protection by reducing fats in the liver, reducing liver weight, size, and enzymes. In other words, it decreases the causes of metabolic disorders.

\section{Conflicts of Interest}

None.

\section{Acknowledgment}

None.

\section{Funding}

None.

\section{References}

1. Shalaby MA, Hammouda AA. Antiobesity, antioxidant and antidiabetic activities of red Ginseng plant extract in obese diabetic rats. Journal of Intercultural Ethnopharmacology. 2013; 2(3):165-72.

2. Majeed A, Iqbal A, Masood Z, Malik A, Rehman HU, Ullah F, et al. Correlation of Obesity to Daily Diet Intake of Young Girls of Quetta City, Pakistan. World Journal of Zoology. 2015;10(2):54-8.

3. Kawano Y, Cohen DE. Mechanisms of hepatic triglyceride accumulation in nonalcoholic fatty liver disease. Journal of Gastroenterology. 2013;48(4):434-41.
4. Ki SH, Yang JH, Ku SK, Kim SC, Kim YW, Cho IJ. Red ginseng extract protects against carbon tetrachloride-induced liver fibrosis. Journal of Ginseng Research. 2013;37(1):45-53.

5. Szczepaniak LS, Babcock EE, Schick F, Dobbins RL, Garg A, Burns DK, McGarry JD, Stein DT. Measurement of intracellular triglyceride stores by $\mathrm{H}$ spectroscopy: validation in vivo. American Journal of Physiology-Endocrinology And Metabolism. 1999; 276(5):E977-89.

6. Kuo J-J, Chang H-H, Tsai T-H, Lee T-Y. The positive effect of curcumin on inflammation and mitochondrial dysfunction in obese mice with liver steatosis. International journal of molecular medicine. 2012;30(3):673-9.

7. Szczepaniak LS, Babcock EE, Schick F, Dobbins RL, Garg A, Burns DK, McGarry JD, Stein DT. Measurement of intracellular triglyceride stores by $\mathrm{H}$ spectroscopy: validation in vivo. American Journal of Physiology-Endocrinology And Metabolism. 1999; 276(5):E977-89.

8. Altmann SW, Davis HR, Zhu LJ, Yao X, Hoos LM, Tetzloff G, Iyer SP, Maguire M, Golovko A, Zeng M, Wang L. NiemannPick C1 Like 1 protein is critical for intestinal cholesterol absorption. Science. 2004; 303(5661):1201-4.

9. Neary NM, Goldstone AP, Bloom SR. Appetite regulation: from the gut to the hypothalamus. Clinical endocrinology. 2004; 60(2):153-60.

10. Lawto CL, Wales JK, Hill AJ, Blundell JE. Serotoninergic Manipulation, MealInduced Satiety and Eating Pattern: Effect of Fluoxetine in Obese Female Subjects. Obesity. 1995; 3(4):345-56.

11. Lee HJ, Lee YH, Park SK, Kang ES, Kim HJ, Lee YC, Choi CS, Park SE, Ahn CW, Cha BS, Lee KW. Korean red ginseng (Panax ginseng) improves insulin sensitivity and attenuates the development of diabetes in Otsuka Long-Evans 
Tokushima fatty rats. Metabolism-Clinical and Experimental. 2009; 58(8):1170-7.

12. Yuan H-D, Kim SJ, Chung S-H. Beneficial effects of IH-901 on glucose and lipid metabolisms via activating adenosine monophosphate-activated protein kinase and phosphatidylinositol-3 kinase pathways. Metabolism. 2011;60(1):43-51.

13. Bucci LR. Selected herbals and human exercise performance-. The American journal of clinical nutrition. 2000;72(2):624S-36S.

14. Asrih M, Jornayvaz FR. Diets and nonalcoholic fatty liver disease: the good and the bad. Clinical Nutrition. 2014;33(2):186-90.

15. Jiao L, Li B, Wang M, Liu Z, Zhang X, Liu S. Antioxidant activities of the oligosaccharides from the roots, flowers and leaves of Panax ginseng CA Meyer. Carbohydrate polymers. 2014;106:293-8.

16. Von Diemen V, Trindade EN, Trindade MRM. Experimental model to induce obesity in rats. Acta Cirurgica Brasileira. 2006;21(6):425-9.

17. Saba E, Jeon BR, Jeong D-H, Lee K, Goo Y-K, Kim S-H, et al. Black ginseng extract ameliorates hypercholesterolemia in rats. Journal of ginseng research. 2016;40(2):160-8.
18. Lee HJ, Ok HM, Kwon O. Protective effects of Korean Red Ginseng against alcohol-induced fatty liver in rats. Molecules. 2015; 20(6):11604-16.

19. Hafez MM, Hamed SS, El-Khadragy MF, Hassan ZK, Al Rejaie SS, Sayed-Ahmed MM, Al-Harbi NO, Al-Hosaini KA, AlHarbi MM, Alhoshani AR, Al-Shabanah OA. Effect of ginseng extract on the TGF$\beta 1$ signaling pathway in $\mathrm{CCl}$ 4-induced liver fibrosis in rats. BMC complementary and alternative medicine. 2017; 17(1):45.

20. Park TY, Hong M, Sung H, Kim S, Suk KT. Effect of Korean Red Ginseng in chronic liver disease. Journal of ginseng research. 2017; 41(4):450-5.

21. Hong M, Lee YH, Kim S, Suk KT, Bang CS, Yoon JH, Baik GH, Kim DJ, Kim MJ. Anti-inflammatory and antifatigue effect of Korean Red Ginseng in patients with nonalcoholic fatty liver disease. Journal of ginseng research. 2016; 40(3):203-10.

22. Mostafa Abbas Shalaby, Ashraf AbdElkhalik Hamoud. Antiobesity, antioxidant and antidiabetic activities of red Ginseng plant extract in obese diabetic rats. $\mathbf{J}$ Intercult Ethnopharmacol 2013; 2(3):165172. 